\title{
The Binding of Calcium to $\kappa$-Casein and Para $\kappa$-Casein
}

\author{
Tomotada Ono, Mikiko YaHAGI and Satoshi OdAGIRI \\ Department of Agricultural Chemistry, Iwate University, Morioka 020, Japan
}

Received October 22, 1979

\begin{abstract}
The binding of calcium to $k$-casein and para $\kappa$-casein was studied by infrared spectra. The binding of calcium to the phosphoryl groups of $k$-casein reached a plateau above $1 \mathrm{~mm}$ $\mathrm{CaCl}_{2}$, and the binding to the carboxyl groups proceeded linearly up to $3 \mathrm{mM} \mathrm{CaCl}_{2}$, and slowly above $3 \mathrm{mM} \mathrm{CaCl}$, which were nearly identical to the results of $\alpha_{s 1}$-casein previously reported. The binding to carboxyl groups of para $\kappa$-casein proceeded similarly. The conformational changes of $k$-casein accompanying the bindings were determined by circular dichroism and ultraviolet spectra. The obtained results suggest that the hydrophobic sites of $\kappa$-casein are exposed to solvent without a change in secondary structure of the protein. Calcium promoted the dissolution of para $\mathrm{k}$-casein in the presence of urea.
\end{abstract}

$\kappa$-Casein, a component of critical importance for the stability of the casein micelles, is not precipitated by the binding of calcium in contrast of other caseins, and its ultraviolet absorption spectra is known to be shifted to shorter wavelength by calcium. ${ }^{1)}$ Ho and Waugh $^{2}$ clarified directly that calcium bound to an organic phosphate group of $\kappa$-casein. Dickson and Perkins ${ }^{3 /}$ determined the amount of alkaline-earth-metal cations bound to $k$ casein. However, the mechanism and sites of the binding are not fully elucidated. The casein micelle is known to be formed by the interaction between dephospholylated $\kappa$-casein and other caseins, ${ }^{1,5)}$ but to be not in the case of $k$-casein of which carboxyl groups were esterified. ${ }^{6)}$ Therefore, in order to elucidate each binding mechanism of calcium to phosphoryl and carboxyl groups, infrared (IR) spectra of $\kappa$-casein were measured at various concentrations of calcium. Then, conformational changes of $k$-casein by the binding of calcium were followed by ultraviolet (UV) difference spectra and circular dichroism (CD) spectra measurements.

\section{EXPERIMENTAL}

Materials. $\quad \kappa$-Casein was prepared from the pooled milk of Holstein cows by a modification ${ }^{12}$ of the method of Zittle and Custer." The final solution was filtered through $0.45 \mu$ Millipore filter, and $20 \mathrm{~mm}$ trisodium ethylenediaminetetraacetate was added to it. This solution was dialyzed against deionized water at $4^{\circ} \mathrm{C}$, and freeze-dried. $\kappa$-Casein thus prepared was confirmed to contain a little other casein components by the disc gel electrophoresis containing $6 \mathrm{M}$ urea. ${ }^{8}$ )

Chymosin (rennin) from calf stomach was purchased from Sigma Chemical Co., and other chemicals were of guaranteed reagent grade.

Sample solutions. The $\kappa$-casein solution for IR measurement were prepared by the adjusting the $\mathrm{pH}$ to 7.0 with $0.1 \mathrm{~N} \mathrm{NaOH}$ after the addition of $\mathrm{CaCl}_{2}$, and finally contained $0.2 \% \kappa$-casein and $\mathrm{CaCl}_{2}$ of zero to $15 \mathrm{~mm}$. The sample solutions of para $\kappa$-casein were prepared as follows. The $\kappa$-casein solutions were treated by chymosin (describes after), and centrifuged at $1000 \times g$ for $30 \mathrm{~min}$. The aggregates were suspended in the solutions containing the same amount of $\mathrm{CaCl}_{2}$ to previous $\kappa$-casein solutions.

The sample solutions for UV difference spectra and $\mathrm{CD}$ measurements containing $0.1 \% \kappa$-casein, $0.05 \mathrm{M}$ dithiothreitol, and $\mathrm{CaCl}_{2}$ of zero to $70 \mathrm{~mm}$ in $0.01 \mathrm{M}$ imidazole buffer of $\mathrm{pH} 7.0$ and ionic strength 0.07 (standard buffer) were allowed to stand for more than one hour.

Chymosin treatment. The ratio of chymosin to $\kappa$-casein was $1: 20(\mathrm{w} / \mathrm{w})$ and this amount of chymosin clotted skim milk at $35^{\circ} \mathrm{C}$ in $4 \mathrm{~min}$. The treatment was carried out at $35^{\circ} \mathrm{C}$ for one hour.

Dissolution of para $\pi$-casein aggregates by urea. Para $\kappa$-casein aggregates obtained above were suspended to each standard buffer containing $0,5,10,25$, 50 , or $100 \mathrm{~mm} \mathrm{CaCl}$. Then, urea dissolved into the standard buffers was added to each suspension in the same buffer. These suspensions were shaken for one hour, centrifuged at $1000 \times g$ for $15 \mathrm{~min}$, and the 
absorbance of the supernatant was determined at $280 \mathrm{~nm}$.

Infrared measurements. Infrared spectra were measured by a Hitachi 215 infrared spectrophotometer. $\mathrm{KBr}$ pellets were prepared from $100 \mathrm{mg} \mathrm{KBr}$ and the dried samples obtained as follows. Each one $\mathrm{ml}$ of sample solutions was quickly frozen by dropwise addition into the test tubes containing liquid nitrogen, and lyophilized.

Ultraviolet difference spectra. Ultraviolet difference spectra were measured by a Hitachi 200-10 spectrophotometer equipped with Hitachi $057 \mathrm{X}-\mathrm{Y}$ recorder setting the full scale to 0.1 optical density. A sample solution in the absence of calcium was positioned at the reference side. Difference molar extinction, $\Delta \varepsilon$, was calculated from the molecular weight of $\kappa$-casein, $19,023 .^{9)}$

Circular dichroism. Circular dichroism measurements were carried out by a Jovin Yvon-Union Giken dichrograph mark III-J. Molecular ellipticity, [ $\theta]$, was obtained from the mean residue molecular weight, 112.6, which was calculated from the data of Mercier et $a l^{\text {(2) }}$

\section{RESULTS}

\section{Binding of calcium to $\kappa$-casein}

Infrared spectrum of $k$-casein was changed by the addition of calcium as shown in Fig. 1 . It is known that the absorption bands at about 970 and $1400 \mathrm{~cm}^{-1}$ show an existence of phosphate group $\mathrm{s}^{101}$ and of free carboxyl groups, ${ }^{11)}$

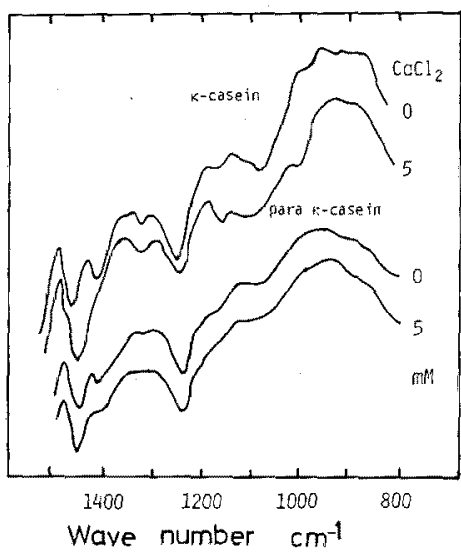

Fig. 1. Infrared Spectra of $\kappa$-Casein and Para $\hbar-$ Casein with or without Calcium.

$\mathrm{KBr}$ pellets were prepared from the $0.2 \% \kappa$-casein solution or $0.2 \%$ para $\kappa$-casein suspension with or without $5 \mathrm{mM} \mathrm{CaCl}_{2}$. respectively, and that the band at about 970 $\mathrm{cm}^{-1}$ shifts to $1000 \mathrm{~cm}^{-1}$ and the one at 1400 $\mathrm{cm}^{-1}$ decreases by binding of calcium. The results in Fig. 1 show that calcium bound to phosphate and carboxyl groups of $\kappa$-casein. These spectra of $\mathrm{KBr}$ pellets agreed with those obtained by Ho and Waugh ${ }^{21}$ using dry film. The absorption band of $\kappa$-casein at $970 \mathrm{~cm}^{-1}$ was smaller than that ${ }^{12)}$ of $\alpha_{\mathrm{s}^{1}}$-casein. It reflects that $\kappa$-casein has only one organic phosphate group per molecule. ${ }^{9)} \quad$ Infrared spectra of para $\kappa$-casein had no absorption band of phosphoryl group at 970 or $1000 \mathrm{~cm}^{-1}$ but the band at $1400 \mathrm{~cm}^{-1}$ was changed by the addition of calcium as shown in Fig. 1. This result shows that the macropeptide containing the phosphoryl group was cleaved from $\kappa$-casein by chymosin and that calcium bound to para $\kappa$-casein through carboxyl groups.

\section{Binding mechanism of calcium}

The measurements of calcium binding to $\alpha_{\mathrm{si}}{ }^{-}$ casein were possible by the IR measurement of $\mathrm{KBr}$ pellets of quickly freeze-drying protein. ${ }^{12)}$ The binding mechanism to $k$-casein was measured by this method. The change of carboxyl groups by the binding of calcium can be estimated from the difference between absorptions at $1445 \mathrm{~cm}^{-1}$ and $1400 \mathrm{~cm}^{-1.21}$ The difference between the absorptions, and

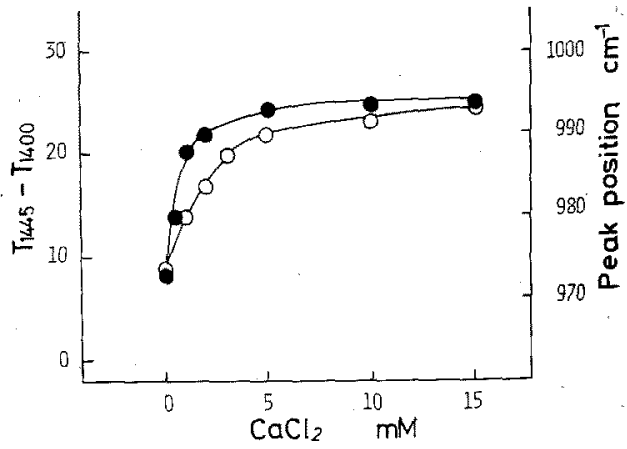

FIG. 2. Changes of Absorption Bands of Phosphoryl and Carboxyl Groups in $\kappa$-Casein by Calcium.

$\mathrm{KBr}$ pellets were prepared from the solutions containing $0.2 \% \kappa$-casein and various amounts of $\mathrm{CaCl}_{2}$ at $\mathrm{pH} 7.0$. $\quad$, peak position of the absorption band of phosphoryl group; $O$, changes of the absorption band of carboxyl groups as difference transmittance between in 1445 and $1400 \mathrm{~cm}^{-1}$. 
the extent of shift of absorption at $980 \mathrm{~cm}^{-1}$ (phosphoryl group) as to $\kappa$-casein are shown in Fig. 2. The steep shift of absorption band of phosphoryl group was observed up to $1 \sim$ $2 \mathrm{mM} \mathrm{CaCl}$, and on the other hand an absorption of carboxyl group at $1400 \mathrm{~cm}^{-1}$ decreased linearly up to about $3 \mathrm{mM} \mathrm{CaCl}_{2}$, and then a slow decrease was observed above $3 \mathrm{~mm}$. Since this process agreed with that of

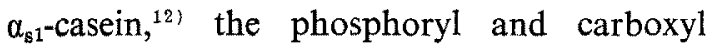
groups of $\kappa$-casein are considered to be constructed in the molecule in analogy with $\alpha_{\mathrm{s}^{-}}$casein.

The binding of calcium to the carboxyl group of para $\kappa$-casein was measured by IR spectroscopy and is shown in Fig. 3. Although the absorption band of para $\kappa$-casein at 1400 $\mathrm{cm}^{-1}$ was smaller than that of $\kappa$-casein, the change of absorption by calcium was similar to that of $\kappa$-casein.

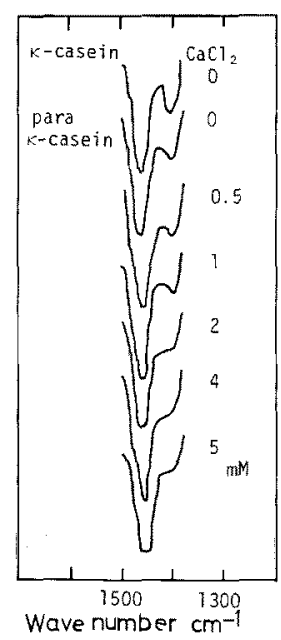

Fig. 3. Effects of Calcium on Absorption Band of Carboxyl Groups in Para $\kappa$-Casein.

Samples for $\mathrm{KBr}$ pellets contained $0.2 \%$ para $\kappa$-casein and various amounts of $\mathrm{CaCl}_{2}$.

\section{Conformational changes of $x$-casein by calcium}

The changes of secondary structure of $k$ casein by calcium were followed by CD measurements and are shown in Fig. 4. The CD spectrum of $\kappa$-casein had a negative maximum at about $215 \mathrm{~nm}$. This $C D$ spectrum was not changed by addition of $40 \mathrm{mM} \mathrm{CaCl}{ }_{2}$. There-

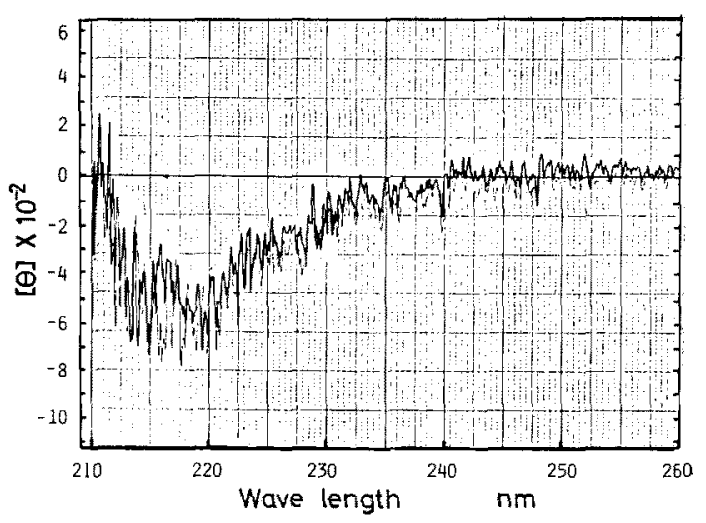

FIG. 4. Circular Dichroism Spectra of $\kappa$-Casein with or without Calcium.

These samples contained $0.084 \% \kappa$-casein with (-) or without $(\rightarrow) 40 \mathrm{mM} \mathrm{CaCl}_{2}$ in standard buffer.

fore, it is considered that the secondary structure of $\kappa$-casein was not changed by binding of calcium.

In order to elucidated the changes of side chains of $\kappa$-casein, the behavior of tyrosyl and tryptophyl residues was investigated with UV difference spectra. $\Delta \varepsilon_{287}$ decreased by addition of $\mathrm{CaCl}_{2}$ and reached to a plateau above $20 \mathrm{mM}$ $\mathrm{CaCl}_{2}$ as shown in Fig. 5. This means that the tryptophyl and tyrosyl residues of $\kappa$-casein were exposed to solvent. $\kappa$-Casein must be unfolded or dissociated by calcium. This change did not take place by the addition of $\mathrm{NaCl}$ of the same ionic strength as calcium. Since this result was not accompanied by changes of IR spectra below $5 \mathrm{~mm} \mathrm{CaCl}_{2}$

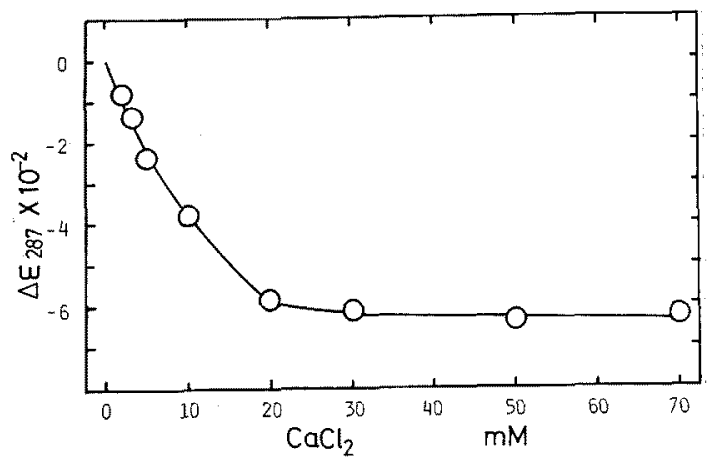

FrG. 5. Effect of Calcium Concentration on Molar Extinction of $r$-Casein.

These samples contained $0.1 \% \pi$-casein, $0.5 \mathrm{~mm}$ dithiothreitol and $\mathrm{CaCl}_{2}$ of zero to $70 \mathrm{~mm}$ in standard buffer. 
(Fig. 2), the change of side chain might be correlated to the change of carboxyl group above $3 \mathrm{~mm}$.

\section{Conformational change of $\kappa$-casein by urea}

The conformation of protein is generally unfolded by urea. $\kappa$-Casein seemed to be unfolded or dissociated by calcium as described above. The effect of calcium on the change of $\kappa$-casein by urea was investigated with UV difference spectra. As shown in Fig. 6, $\Delta \varepsilon_{287}$ values showed minimum at about $3.6 \mathrm{M}$ urea in the presence or the absence of calcium, and increased above $3.6 \mathrm{M}$ because of solvent effect. $^{13)} \quad \Delta \varepsilon_{287}$ value in the absence of calcium was higher by 600 than that in the presence of $50 \mathrm{mM} \mathrm{CaCl}_{2}$. It is realized that the unfolding of $\kappa$-casein was completed in $3.6 \mathrm{M}$ urea either in the presence or the absence of calcium. The conformation destroyed by calcium must be a part of the conformation destroyed by urea, but the effect of calcium may be different from that of urea.

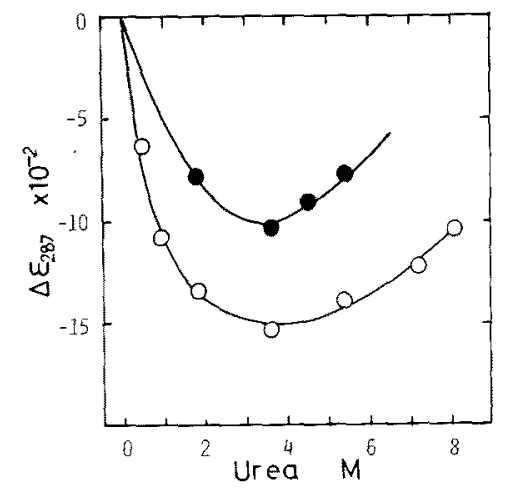

FIG. 6. Effect of Calcium on Change of Molar Extinction of $\kappa$-Casein by Urea.

The samples containing $0.1 \% \mathrm{x}$-casein, and $0.5 \mathrm{~mm}$ dithiothreitol with (๑) or without (O) $50 \mathrm{mM} \mathrm{CaCl}$ in standard buffer were used for urea-concentration difference spectra.

\section{Dissolution of para $\kappa$-casein by urea}

Since the conformational change of $\kappa$-casein was caused by calcium in a similar manner by urea, effect of calcium on the dissolution of para $\kappa$-casein by urea was investigated. More than $90 \%$ of para $\kappa$-casein aggregate was solu-

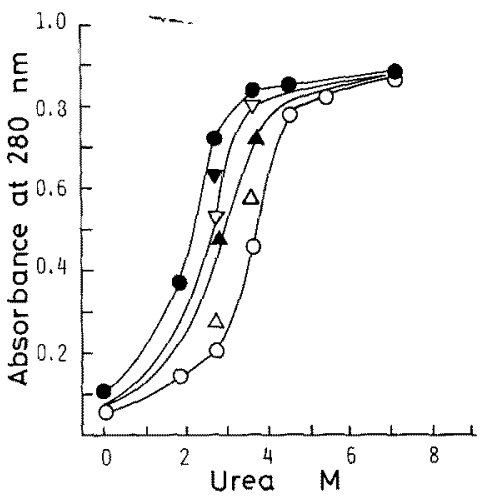

Fyg. 7. Effect of Calcium on Dissolution of Para $\kappa$-Casein by Urea.

Urea was added to each suspension of $0.1 \%$ para $\kappa$-casein containing $0(\bigcirc), 5(\triangle), 10(\Lambda), 25(\nabla), 50(\nabla)$, or $100 \mathrm{mM}(\bullet) \mathrm{CaCl}_{2}$ in standard buffer.

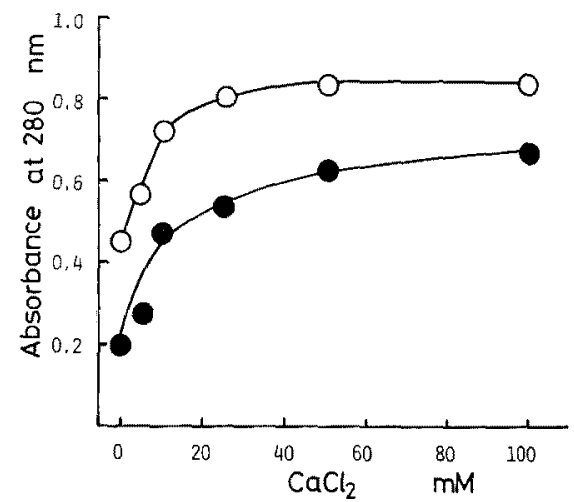

Frg. 8. Dissolution of Para $x$-Casein in Urea Solution by Calcium.

These samples contained $0.1 \%$ para $k$-casein and $2.7 \mathrm{M}(\bullet)$ or $3.6 \mathrm{M}(\mathrm{O})$ urea in standard buffer. Calcium chloride was added from zero to $100 \mathrm{~mm}$ against these samples.

bilized at $4.5 \mathrm{M}$ urea in the absence of calcium as shown in Fig. 7. The para $\kappa$-casein can be solubilized at lower concentration of urea with increasing calcium. The dissolution of para $\kappa$-casein by calcium is shown in Fig. 8. Para $\kappa$-casein at $2.7 \mathrm{M}$ urea was not completely dissolved even by addition of $100 \mathrm{mM} \mathrm{CaCl}$. Para $\kappa$-casein at $3.6 \mathrm{M}$ urea was almost dissolved above $25 \mathrm{mM} \mathrm{CaCl}_{2}$. The dissolution of para $\kappa$-casein by urea was promoted by addition of $\mathrm{CaCl}_{2}$. It is considered that para $x$-casein aggregate becomes loose by calcium and was dissolved readily by urea, and that 
the conformation of para $\kappa$-casein may be changed by calcium as well as that of $\kappa$-casein.

\section{DISCUSSION}

$\kappa$-Casein contains many proline residues as well as other caseins. Therefore, it is known that $\kappa$-casein has a disorganized structure. ${ }^{14,15}$ Herskovits ${ }^{15}$ ) estimated that $\kappa$-casein has a little $\alpha$-helical form from the parameters of Moffit and Yang and of Shechter and Blout. These parameters offer no information of $\beta$ structure. The result from $C D$ measurement suggests a possible existence of $\beta$-structure by a minimum absorption at $215 \mathrm{~nm}$. In any event, it is evident that $\kappa$-casein has a structure other than a random coil. This structure is considered to be a rigid form which does not change by calcium.

Calcium may bind to the sites of negative charge. The negative sites of $\kappa$-casein which localize in the $\mathrm{N}$-terminal and $\mathrm{C}$-terminal regions ${ }^{9 /}$ must bind to the positive sites. The innermolecular bonds may be severed by the binding of calcium, and the exposure of the sites to solvent may be caused. Although the exposure by calcium was considered to be a part of unfolding caused by urea, the urea does not severe the electrostatic or ionic bonds, but does the hydrogen or hydrophobic bonds. ${ }^{16)}$ Therefore, the electrostatic or ionic bond must be nearby the hydrogen or hydrophobic bond in $\kappa$-casein molecule.

The negative site in para $\kappa$-casein localizes at $\mathrm{N}$-terminal region because the macropeptide containing the negative-charged C-terminal region is cut off from $\kappa$-casein. Calcium may bind to the negative site and may sever the electrostatic or ionic bonds by positive repulsion. Further, the positive repulsion may sever the hydrogen or hydrophobic bonds. Therefore, para $\kappa$-casein in the presence of calcium can be dissolved by lower concentration of urea.

After all, the hydrophobic sites of $\kappa$-casein is exposed to solvent by calcium. These properties of $\kappa$-casein are considered to play an important role in the formation of casein micelle.

Acknowledgment. Authors are greatly indebted to Dr. Hiroshi Meguro and Dr. Toshio Konno of Department of Agricultural Chemistry, Tohoku University for measuring $C D$ spectra.

This research was supported in part by the research grant from the Ministry of Education, Japan.

\section{REFERENCES}

1) H. Chiba, K. Tatsumi, R. Sasaki, and E. Sugimoto, Nippon Nögeikagaku Kaishi, 44, 364 (1970).

2) Chien Ho, and David F. Waugh, J. Am. Chem. Soc., 87, 889 (1965).

3) I. R. Dickson, and D. J. Perkins, Biochem. J., 124, 235 (1971).

4) L. Pepper, and M. P. Thompson, J. Dairy Sci, 46, 764 (1963).

5) K. Yamauchi, S. Takemoto, and T. Tsugo, Agric. Biol. Chem., 31, 54 (1967).

6) S. Kaminogawa, R. Sakai, and K. Yamauchi, Nippon Nögeikagaku Kaishi, 47, 129 (1973).

7) C. A. Zittle, and J. H. Custer, J. Dairy Sci., 46, 1183 (1963).

8) K. Aoki, E. Nakano, and Y. Ohoi, "Denkieido Jikkenho", Hirokawa Publishing Co., Tokyo, 1966, p. 148.

9) J. C. Mercier, G. Brigton, and B. RibadeauDumas, Eur. J. Biochem., 35, 222 (1973).

10) D. E. C. Corbridge, J. Appl. Chem., 6, 456 (1956).

11) G. Ehrich, and G. B. B. M. Sutherland, J. Am. Chem. Soc., 76, 5268 (1954).

12) T. Ono, S. Kaminogawa, S. Odagiri, and $K$. Yamauchi, Agric. Biol. Chem., 40, 1717 (1976).

13) T. T.Herskovits, and M. Laskowski Jr., $J$. Biol. Chem., 237, 2481 (1962).

14) M. E. Noelken, and M. Reibstein, Arch. Biochem. Biophys., 123, 397 (1968).

15) T. T. Herskovits, Biochemistry, 5, 1018 (1966).

16) K. Hamaguchi, "Tanpakushitsu no Ritaikozou,"” Kyoritsu Syuppan Co., Ltd., 1967, p. 127. 